\title{
Women and Physics in Brazil: Publications, Citations and H Index
}

\author{
Jeferson J. Arenzon ${ }^{\mathrm{a}}$, Patrícia Duarte ${ }^{\mathrm{a}}$, Solange Cavalcanti ${ }^{\mathrm{b}}$, \\ and Marcia C. Barbosa ${ }^{\mathrm{a}}$ \\ ${ }^{a}$ Instituto de Física, Universidade Federal do Rio Grande do Sul, Porto Alegre; \\ ${ }^{b}$ Departamento de Física, Universidade Federal de Alagoas, Maceió
}

\begin{abstract}
In the last decade, the main Brazilian research funding agencies, CNPq and CAPES, have introduced gender projects aimed to understand the situation of women in general and in science in particular. These projects have led to an increased awareness of the problem. There is still a long way to go in the quest for equal access to opportunities and resources. This paper compares the production and quality of work of female scientists with their male colleagues in the physics and astronomy grant-funded research community in Brazil.
\end{abstract}

Keywords: Brazil, women in physics

PACS: 01.75. $+\mathrm{m}, 01.78 .+\mathrm{p}$

In the last decade, the main Brazilian research funding agencies, CNPq (Conselho Nacional de Pesquisas) and CAPES (Coordenação de Aperfeiçoamento em Estudos Superiores) have introduced gender programs, such as four months maternity leave for graduate students, and an annual grant for gender studies. The grant funds are directed toward sociological projects to identify barriers that hinder women from progressing in their careers, a worldwide phenomenon well-known as the glass ceiling [1]. However, the results are qualitative and are still far from giving a clear picture about the differences between the participation of male and female scientists.

$\mathrm{CNPq}$ offers research-productivity fellowships for professors at the national universities. The fellowship gives these professors, known as "CNPq-researchers" a modest salary supplement. CNPq-researchers are rewarded at one of five levels on the basis of productivity, measured by number of papers published on indexed journals, number of graduate student supervisions, how often their work has been cited by other researchers, and $\mathrm{h}$ index, a measurement that aims to describe the scientific productivity and impact of a researcher using the scientist's most cited papers and the number of citations they have received in other publications. The highest $\mathrm{CNPq}$ level is $1 \mathrm{~A}$ (after 1D, 1C, and 1B) and the lowest is 2, for junior researchers.

In physics, only about $10 \%$ of the CNPq-researchers are female, even though the percentage of female professors in physics is about $20 \%$ [2] and the average number of publications is higher than or about the same as their male colleagues at most levels [3]. As shown in the left panel of Figure 1, in 2005 the average number of publications of female physicists at levels 2 and 1B was higher than the average number of publications of their male colleagues at the same level, and at levels $1 \mathrm{C}$ and $1 \mathrm{D}$ the average number of publications was about the same for men and women. This result, together with the observation that only two women were level $1 \mathrm{~A}$ researchers, led CNPq and CAPES to consider promoting more women and introduce new policies.

The same study was carried out five years later, in 2010 [4]. The results, illustrated in the right panel of Figure 1, show female physicists at level 1D with a higher average number of publications, probably the result of the natural promotion from the level 2 into level 1D that usually occurs at the five years' window. In the 2010 data the new entries at level 2 have the same average number of publications when male and female are compared, which indicates that the awareness generated by the previous studies was a positive factor.

The promotion of a few female physicists from level 1B to level 1A that occurred after 2005 improved the female representation in this top level, which, in 2010, shows the same profile when male and female are compared. Level 1B exhibits in 2010 a discrepancy due to one or two cases of women with lower number of publications at that level. Level 1B now has only five female researchers and a single fluctuation (one researcher with a low number of publications) at this level would explain why the females at level $1 \mathrm{~B}$ have an average number of publications lower than their male counterparts.

Figure 2 compares the impact of the papers published by men and women physicists at each CNPq fellowship level in 2010 by plotting the number of citations (upper panels) and the $\mathrm{h}$ indexes (lower panels) of all CNPq-researchers, as a function of the researchers' levels. We observe that male scientists (left panel) exhibit a linear trend both in the citations and $\mathrm{h}$ indexes, while female scientists (right panel) show no linearity. The overshoot at level 1D is due to the effect of the average number of publications and reflects the promotion of the highly productive female scientists, underclassified at level 2, in 2005.

Women in Physics

AIP Conf. Proc. 1517, 78-79 (2013); doi: 10.1063/1.4794228

(C) 2013 American Institute of Physics 978-0-7354-1140-1/\$30.00 



FIGURE 1. Average number of publications for male and female physicists at each $\mathrm{CNPq}$ fellowship level 2005 [3] and 2010 [4].
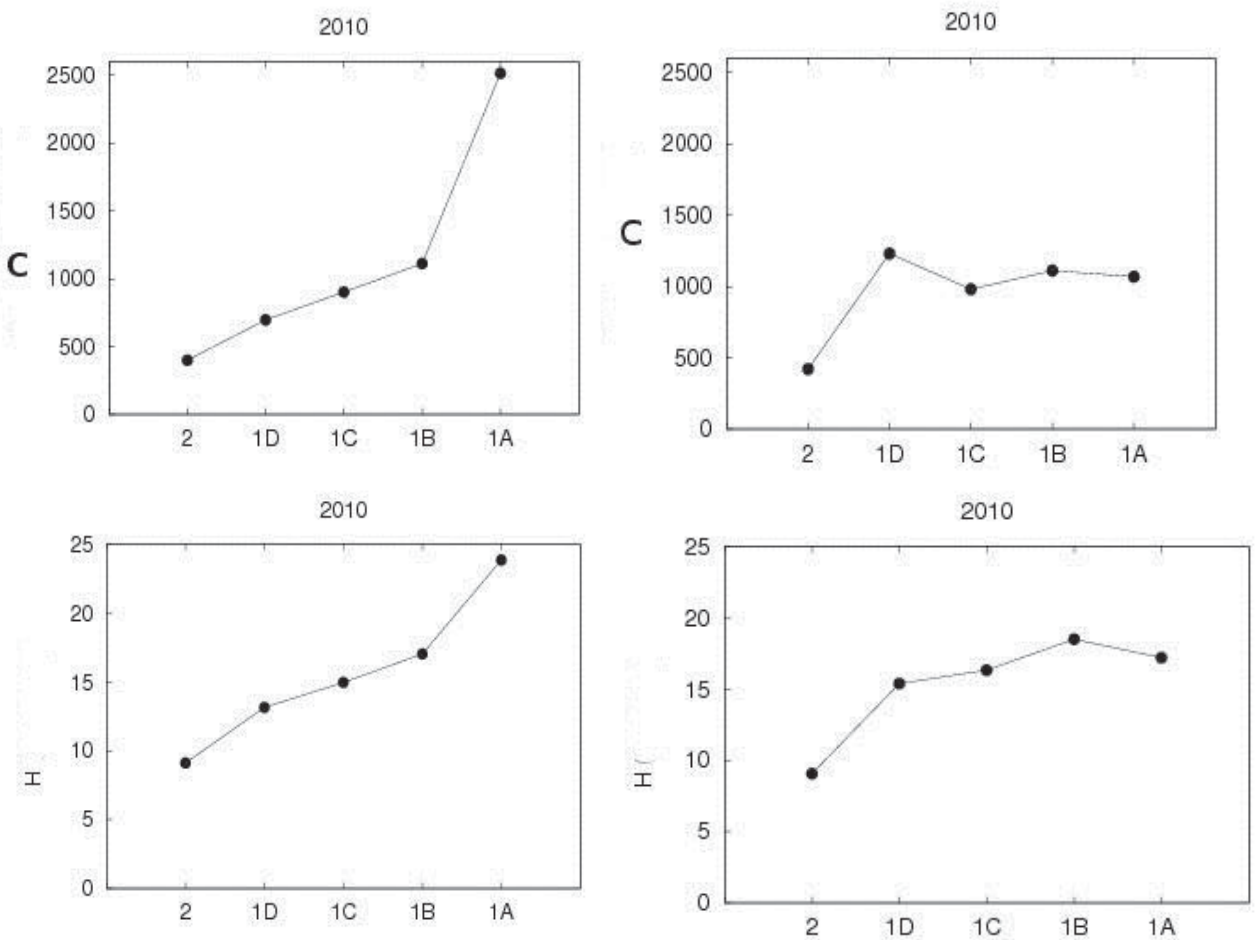

FIGURE 2. Top row: Average number of citations for male (left) and female (right) physicists at different levels of their careers. Bottom row: Average h indexes for male (left) and female (right) physicists at different levels of their careers.

One may conjecture that the relatively low numbers of citations and $\mathrm{h}$ indexes in level $1 \mathrm{~A}$ attributed to women reflects the difficulty in networking that senior female physicists endure. This analysis is preliminary and further studies are required to shed some more light on this conjecture.

\section{ACKNOWLEDGMENT}

We thank the Brazilian Physical Society for the funds for one of us attending the 4th IUPAP International Conference on Women in Physics.

\section{REFERENCES}

1. M. Burin, http://dspace.uces.edu.ar:8180/dspace/handle/123456789/263.

2. Data collected from www.cnpq.br.

3. J.J. Arenzon and M.C. Barbosa, www.if.ufrgs.br/ barbosa/cnpq-2005.html.

4. Patrícia Duarte, M.C. Barbosa, and J.J. Arenzon, www.if.ufrgs.br/ barbosa/cnpq.html. 
Copyright of AIP Conference Proceedings is the property of American Institute of Physics and its content may not be copied or emailed to multiple sites or posted to a listserv without the copyright holder's express written permission. However, users may print, download, or email articles for individual use. 